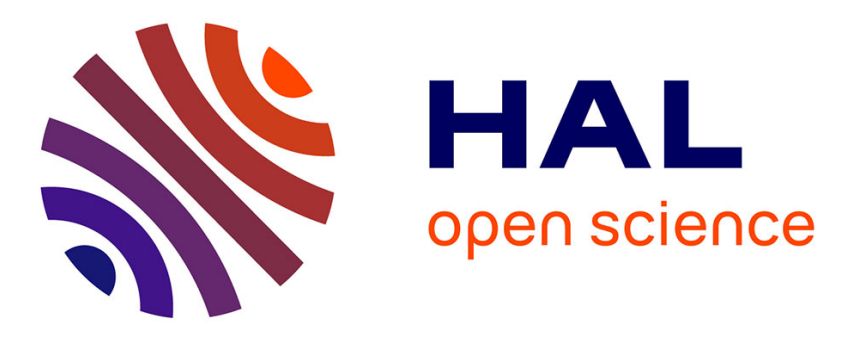

\title{
The co-design of scenarios for a didactic-based E-learning system viewed as an adaptive virtual document
}

Jean Louis Tetchueng, Serge Garlatti, Sylvain Laubé, Yves Kuster, Oussama

Kassem Zein, Yvon Kermarrec

\section{To cite this version:}

Jean Louis Tetchueng, Serge Garlatti, Sylvain Laubé, Yves Kuster, Oussama Kassem Zein, et al.. The co-design of scenarios for a didactic-based E-learning system viewed as an adaptive virtual document. 2nd IEEE International Conference on Information \& Communication Technologies, 2006, Damascus, Syria. pp.583-588. hal-00197388

\section{HAL Id: hal-00197388 \\ https://telearn.archives-ouvertes.fr/hal-00197388}

Submitted on 14 Dec 2007

HAL is a multi-disciplinary open access archive for the deposit and dissemination of scientific research documents, whether they are published or not. The documents may come from teaching and research institutions in France or abroad, or from public or private research centers.
L'archive ouverte pluridisciplinaire HAL, est destinée au dépôt et à la diffusion de documents scientifiques de niveau recherche, publiés ou non, émanant des établissements d'enseignement et de recherche français ou étrangers, des laboratoires publics ou privés. 


\section{The Co-Design of Scenarios for a Didactic-based E-learning System viewed as an Adaptive Virtual Document}

\author{
Serge Garlatti, \\ J-L. Tetchueng, \\ ENSTB, CS. Department \\ Technopôle Brest Iroise \\ CS 83818, 29238 Brest \\ Cedex 3, France \\ serge.garlatti@enst-bretagne.fr, \\ jl.Tetchueng@enst-bretagne.fr
}

\author{
Sylvain Laubé, \\ Yves Kuster \\ CREAD, IUFM de \\ Bretagne, site de Brest, \\ 8 rue d'Avranches 29200 \\ Brest, France \\ sylvain.laube@bretagne.iufm.f \\ r, yves.kuster@bretagne.iufm.fr
}

\author{
O. Kassem Zein \\ Yvon Kermarrec \\ ENSTB, LUSSI Department, \\ Technopôle Brest Iroise \\ CS 83818, 29238 Brest \\ Cedex 3, France \\ Oussama.zein@enst-bretagne.fr \\ yvon.kermarrec@enst-bretagne.fr
}

\begin{abstract}
The design and engineering of E-learning systems must be considered as a transdisciplinary problem requiring the integration of different scientific approaches. The design process of E-learning systems needs to consider several theories, models and artifacts - the e-learning system. We claim it is essential to ensure the traceability and the interpretation of phenomena related to the use of artifacts in studying precisely the relationships between theories, models and artifacts. Consequently, we develop a co-design methodology to deal with these goals. The main contribution of this paper is to describe a methodological approach enabling the co-design of problem-based learning scenarios in sciences which are based on teacher real practices acquired by means of the theory in didactic anthropology of knowledge and to show why we can formalize them in a hierarchical task model to design an adaptive E-learning system.
\end{abstract}

\section{Introduction}

The design and engineering of E-learning systems must be considered as a transdisciplinary problem requiring the integration of different scientific approaches - from computer science, didactic, cognitive psychology, education, etc. The design process leads to an artifact - e-learning system - based on different models which are related to different theories - for instance, activity theory, theory of didactic situations, etc [1]. Consequently, it is very important to study the relationships between theories, models and artifacts to ensure the traceability and the interpretation of phenomena related to the use of artifacts. Such a study is one of the main goals of the MODALES project (Modeling Didactic-based Active Learning Environment in Sciences). The main contribution of this paper is i) to describe a methodological approach enabling the co- design of problem-based learning scenarios in sciences which are based on teacher real practices acquired by means of the theory in didactic anthropology of knowledge ii) to show why we can formalize them in a hierarchical task model [2-5] to design an adaptive Elearning system.

First of all, we briefly present the main goals of the MODALES project and we define our co-design principles. Secondly, the acquisition of the problembased learning scenarios with Chevallard theory is detailed. Thirdly, we introduce the roles of scenarios in the E-learning system design. Finally, conclusions and perspectives are presented.

\section{MODALES Project}

MODALES project is aimed at designing an adaptive E-learning system for probationary teachers, based on real practices. The course topic is about "the air as gas in its static and dynamic aspects: properties, theory and applications" for different categories of probationary teachers - called learners. In our framework, scenarios may change according to the following features: i) the category of learners having intra and inter category variability; ii) the available resources from different domains - physics, didactic and epistemology - which can be determined by teachers iii) distance or face-toface activity according to learner needs and learning policy iv) the sharing of activities between teachers, learners and computers according to learner needs and learning policies. These features will lead to adaptation policies in the E-learning system. The main issue is to design a generic scenario which can deal with most of learning situations. From a generic scenario, the elearning system will compute on the fly a particular scenario dedicated to the current learner and its learning situation. The generic scenario acts as scaffolding in the e-learning system. 
In our framework, the co-design process can be viewed as a swirl model having iterative loops which leads to cooperation between computer scientists and expert teachers by means of repetitive interactions similar to proposal made by Akrich et al 1988 [6]. In such an approach, several models, artifacts will be achieved. Several theories will be used to acquire teacher practices finely and to determine the benefits and the limits of each one in this co-design process. These theories are: activity theory [7], the theory of didactic situations [8] and the theory in didactic anthropology of knowledge [9, 10]. At present, the co-design of scenarios is based on teacher real practices acquired by means of the theory in didactic anthropology of knowledge and is formalized in a hierarchical task model[2-5]. Teachers belong to a community of practices: they share a common knowledge to work together [11]. Scenarios are based on the explicit community knowledge and are a key issue to design the e-learning system and to adapt the delivered course to learners.

\section{The co-design of scenarios}

The schema of the didactic transposition of Perrenoud [12] sums up our methodology to design and to model the learning situations: i) to discover and describe finely the practices and the know-how of teachers and learners, ii) to identify the competences at work (of teachers and learners), iii) to analyze the cognitive resources (knowledge, etc.) used by teachers and learners, iv) to make assumptions about the genesis of competences during learning situations; v) to elaborate devices, situations, planned contents of the curriculum (a formal curriculum vitae) and to implement them (a real curriculum vitae). The co-design has been done in three main stages: 1) design of an initial version of the scenarios by expert teachers, 2) acquisition of the refined scenarios using a theory in didactic anthropology of knowledge $[9,10] 3)$ formalization in a hierarchical task model [2-5]. The stage 1 has been done to initiate the swirl model and the cooperation between expert teachers and computer scientist. The stages 2 and 3 lead to iterative loops investigating theory, models and artifacts in depth. This paragraph is organized as follows: first of all, we describe the first version of scenarios designed by expert teachers; secondly, we introduce the Chevallard theory and the corresponding refinement of scenarios and thirdly we present some features of the hierarchical task models and their relationships with the Chevallard theory.

\subsection{The first version of scenarios designed by expert teachers.}

The learners are probationary teachers: primary school teachers (called PE for "professeur des Ecoles" and secondary school teachers (called PLC for "professeur des Lycées et Collèges": earth/biology sciences and physic. The teachers are considered as experts in education. The course topic is about "the air as gas in its static and dynamic aspects: properties, theory and applications" for different categories of probationary teachers. A common learning scenario Po (whose variables are learners, the expert teacher and the available resources) was built. It shows two phases: 1) construction of professional references for teaching, 2) development of a training sequence implemented in classrooms. A stage is composed of a sequence of activities. Scenarios for PE and PLC in earth/biology sciences and physics were established according to the same procedure: each expert teacher (according to his domain) built a scenario from the common plan Po. He associates to an activity of the two phases a series of information: 1) activation of the phase (if it exists in the scenario); 2) distance or face to face; 3) a description of the available resources and their type (physics, didactic, epistemological / historic); 4) an activity description for learners and teachers. Activities Tij can be refined according to the learner, its group the didactic situation and some others constraints given by the teacher.

Table 1. Common learning scenario Po

\begin{tabular}{|c|c|}
\hline $\begin{array}{l}\text { Phase 1: construction } \\
\text { professional } \\
\text { teaching }\end{array}$ & $\begin{array}{l}\text { Phase 2: construction of a } \\
\text { learning sequence }\end{array}$ \\
\hline T1. define the problem & T1. define the scientific problem \\
\hline T2. read the resources & T2. scientific goals \\
\hline T3. explain the approach & T4. method and know-how goals \\
\hline T4. intermediate report & $\begin{array}{l}\text { T5. Description of the didactic } \\
\text { problem solving method }\end{array}$ \\
\hline T5. achieve the approach & $\begin{array}{l}\text { T6. describe necessary activities } \\
\text { to solve the problem }\end{array}$ \\
\hline T6. write the final report & $\begin{array}{l}\text { T7. Compare the different } \\
\text { approaches }\end{array}$ \\
\hline T7. Compare all the reports & T8. Synthesis \\
\hline
\end{tabular}

\subsection{Scenario refinement using the Chevallard Theory}

The Chevallard theory has been used to deal with the acquisition and the refinement of scenarios. According to this theory, the teacher and learner activity can be described in terms of types of tasks $T$ achieved by techniques $t$ which may be recursively achieved by subtasks $T$ '. This hierarchical structure $T / t$ defines a know-how that leans on an environment composed of a technology $\theta$ (discourse that justifies and explains technique) and a theory $\Theta$ justifying and highlighting the technology. The system composed of $(T / t / \theta / \Theta)$ constitutes an organization articulating the know-how and the knowledge. In our scenarios, this viewpoint is applied at two levels (that we need to make obvious since we consider that these levels constitute the reference for the conception of an adaptive E-learning system: i) the teacher as expert with his own system 
$(T / t / \theta / \Theta)_{\text {teacher }}$; ii) the probationary teacher as learner. His apprenticeship procedure has to evolve the $(T / t / \theta$ $/ \Theta)_{\text {learner }}$ system. We observe six different phases in the educational organization [10]: i) the first encounter with the type of tasks $T_{\text {learner }}(\mathrm{M} 1)$; ii) the exploration of the type of tasks $T_{\text {learner }}$ and the construction of techniques $t$ (M2); iii) the construction of a Technology/Theory relating to technique $t(\mathrm{M} 3)$; iv) the technique work that improves technique and makes it more efficient; v) the institutionalization of the $(T / t / \theta / \Theta)$ system by the teacher (M5); vi) the evaluation (M6). A scenario is composed of two main parts: the first one is dedicated to the "construction of teacher professional references" and the second to "construction of a classroom lesson". We analyzed the two parts of scenarios by means of $(T / t / \theta / \Theta)$ systems and the different phases of the educational organization:

1) Each part has the same structure: a) a problem solving proposal, b) the construction by learners of the Tasks / Technique system for solving the problem, c) construction of a critical discourse on the Tasks / Technique system (the technology construction), d) institutionalization by the teacher which brings a theoretical discourse validating the technology.

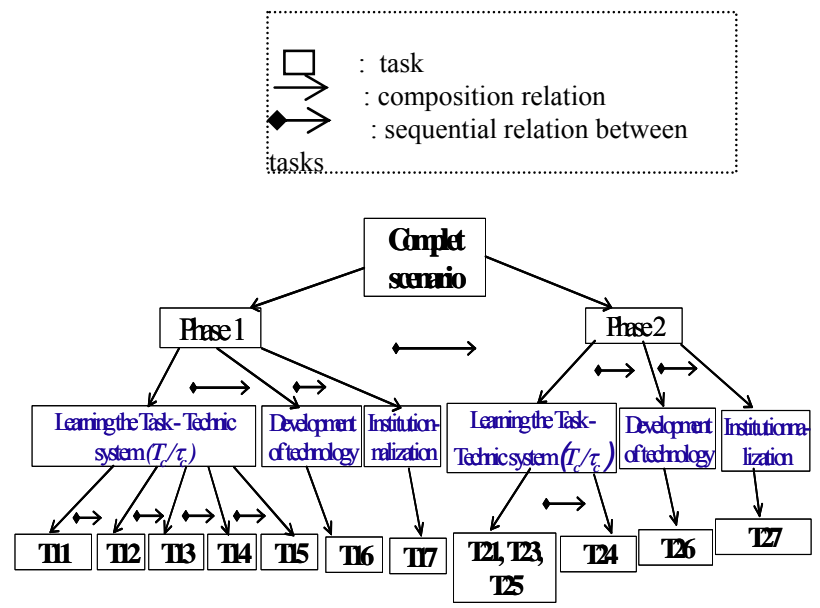

Figure 1. An organization of the stages of the scenario Po.

2) Several pairs Tasks/Technique can be observed for a given problem according to the teacher role:

a) A routine pair: there is no teacher interaction and he did not plan to intervene (for instance, learners are able to read and write). Nevertheless, he could check whether the task is completed on time and could do it on line. The routine pair does not have any learning interest.

b) A problematic pair: the teacher is acting in the learning situation after a period $\Delta \tau$. The value of $\Delta \tau$ gives us a relevant features to analyze different learning situations. More does the teacher intervene quickly in the didactic situation (i.e. $\Delta \tau$ is small), more the Tasks/Technique system is considered as problematic. The learner does not have a routine at all to solve the problem. It is "really" a learning task comparing to the previous pair (routine). Thus, we can show several - didactic situations with such a pair: 1) the first meeting with the problem and the first Tasks/Technique system able to solve the problem. The Tasks/Technique system has to be more detailed and is composed of several sub-tasks which are problematic. Maybe, some of them could be a routine; 2) the work on a problematic Tasks / Technique system after the first meeting. The Tasks/Technique system has to be less detailed than previously and is also composed of several subtasks which are problematic; 3 ) the work on a new Tasks/Technique system to be more efficient, but which is always problematic. There is no routine to solve the corresponding problem.

\subsection{Formalization of the scenarios}

Hierarchical models of tasks represent knowledge about problem solving. Several studies about these models have bee done (for instance, [2-5]). Thus, they can be characterized with lots of properties for describing the problem solving knowledge. In our case, we are only interested in those which enable us to formalize the scenarios. We need to analyze the concepts of task (denoted in italic bold to distinguish them from the tasks in the didactic anthropological theory of the knowledge denoted $\mathrm{T}_{\mathrm{c}}$ ), method, abstract task, elementary task, control structure of tasks and sub-tasks, inheritance and composition graph of tasks.

Within the framework of the Task/Method paradigm of the hierarchical models of tasks, tasks define activities and sub-activities managed by a knowledgebased system (Trichet, 1998). There exist two types of tasks: abstract task and elementary task. An abstract task represents a high level activity which is composed of sub-tasks. Sub- tasks can be abstract or elementary tasks. An elementary task is not composed of sub-tasks. It can be achieved by a simple procedure - for instance, an information retrieval process, a particular human computer interaction, etc. Thus, an abstract task can be broken down recursively into sub tasks until having elementary tasks. A method describes how a particular task can be achieved. Methods define the control structure which allows the recursive decomposition of tasks into sub-tasks and the control structure defines sub-task order at runtime. For a given task, several methods can be used for achieving it. In this case, a mechanism must select dynamically the relevant method for achieving the task according to the current problem solving context. Moreover, tasks are also organized in a inheritance graph which enable us to refine the tasks definition in one (or several) more specific tasks.

A comparison of the concepts (and their properties) of the Chevallard theory applied to the scenarios and those of the hierarchical models of tasks shows semantic similarities between them. Indeed, according to theirs respective interpretations and properties, we can establish the following connections: 
- Tasks and sub tasks $\mathrm{T}_{\mathrm{c}}$ of the Chevallard theory, can be represented by the concept of task in the hierarchical model of tasks.

- Techniques which are a way of achieving a task $t_{c}$ can be represented by the concept of method describes above.

- Amongst task $\mathrm{T}_{\mathrm{c}}$ of the Chevallard theory, we can distinguish «learning» task (call LT task, , corresponding to a problematic pair) and task without learning interest (call NLT task, corresponding to a routine pair); such as the first one can be broken down recursively into LT and NLT tasks and the second one cannot be decomposed into LT tasks. With this, we can represent a composition graph of LT task, in which, LT tasks are seen as abstract tasks and NLT tasks as elementary tasks since they cannot be decomposed into LT tasks.

- The decomposition of a task $T_{c}$ in sub task $T_{c}$ by a technique can be represented by the decomposition mechanism of a task by a method in the hierarchical model of tasks.

- The Problematic/Routine Category of a task $\mathrm{T}_{\mathrm{c}}$ for a given learner is not completely defined. Nevertheless, it can already be use to determine an appropriate technique for the accomplishment of the task $T_{c}$. Its therefore a relevant parameter for the selection of the suitable method for the task,

- The Tij stages of the scenario (table 1) are specialized according to specific features of learner. This can be viewed as a specialization of the definition of the task and is represented in an inheritance graph within the hierarchical models of tasks.

The list above shows some representations of concepts and properties of the Chevallard theory with concepts and mechanisms of the hierarchical models of tasks. This formalization shows that it is possible to transpose in a hierarchical model of tasks the $T_{c} / \tau_{c}$ structure of the Chevallard organization of learner and teacher. A hierarchical models of tasks enables us to transpose the hierarchical structure $T_{c} / \tau_{c}$ of Chevallard theory and their properties into a computer-based model. But, it will enable us to share activities among actors and to manage distance and face-to-face activities.

At present, it is not yet possible to formalize all aspects of the know-how of the teachers because, the description of the scenarios is not finished. In other words, the co-design process has to go to the next loop of our swirl model.

\section{Scenario roles in the E-learning system design}

The adaptive E-learning system can be viewed as an adaptive virtual document. It will use a flexible composition engine, called SCARCE - SemantiC and
Adaptive Retrieval and Composition Engine based on a semantic web approach [13-15]. SCARCE is the core of ICCARS project (Integrated and Collaborative Computer Assisted Reporting System), the CANDLE European project (Collaborative And Network Distributed Learning Environment) and KMP project (Knowledge Management Portal, RNRT Project). In our framework, an adaptive virtual document consists of a set of resources, their corresponding metadata, different ontologies and an adaptive composition engine which is able to select the relevant resources, to organize and to assemble them by adapting the delivered document to the learner needs and the current learning situation. To provide flexibility, selection, organization and adaptation are parameters of the composition engine and lead to a specification. This specification is called a generic scenario. It has to deal with most of learning situations. From a generic scenario, the e-learning system will compute on the fly a particular scenario dedicated to the current learner and its learning situation. The generic scenario acts as scaffolding in the e-learning system.

SCARCE uses four loosely coupled ontologies which are: metadata ontology at the information level which describes the indexing structure of resources, some index values are taken in the domain and document ontologies; domain ontology representing knowledge in a specific area - physics, didactic, epistemology; document ontology consisting of a document model organization and selection - and an adaptation model. This document model and adaptation model become a didactic scenario ontology based on a hierarchical task model and a new adaptation model based on the adaptation categories required by MODALES Project; a user ontology which defines different stereotypes categories of probationary teachers and teachers - and individual features. Metadata schema, ontologies and specifications are based on the explicit common knowledge shared by all community members. In other words, scenarios are key issue to design the document ontology, metadata schema and specifications.

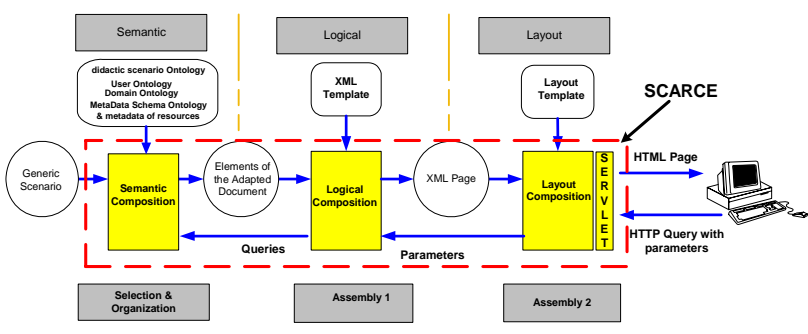

Figure 2. The composition engine architecture

In a digital document, three different views may coexist: semantic, logical and layout. Each view has a specific structure organizing it. The semantic structure of a document conveys the organization of the meaning of the document content. The semantic structure can play 
the role of a site map in a hypermedia document. The logical structure reflects the syntactic organization of a document. The layout view describes how the documents appear on a device. Our composition engine is divided into three engines: semantic composition, logical composition and layout composition (cf. Fig. 1) according to these three views. For us, these views are closely related to the semantic web architecture: i) semantic: logic, ontology, RDFS/RDF, ii) logical: syntactic level encoded in XML, iii) layout: XSL/XSLT. The four mechanisms of virtual documents are implemented as follows: selection, filtering and organization are achieved in the semantic composition; assembly is divided into logical and layout compositions.

In comparison with the current version of SCARCE, we need to modify/extend the document model and the adaptation model to deal with MADALES requirements and the semantic composition engine - at least. The new version of the semantic composition engine must be able to manage a hierarchical task model and a new adaptation model dealing with the Chevallard theory and the teacher practices.

\section{Conclusion}

The design and engineering of E-learning systems must be considered as a transdisciplinary problem requiring the integration of different scientific approaches - from computer science, didactic, cognitive psychology, education, etc. For these reasons, we develop a co-design methodology able to study the relationships between theories, models and artifacts to ensure the traceability and the interpretation of phenomena related to the use of artifacts.

Thus, we have described a methodological approach enabling the co-design of problem-based learning scenarios in sciences. This co-design process is viewed as a swirl model having iterative loops. It is based on teacher real practices acquired by means of the theory in didactic anthropology of knowledge. We have also showed why and how we can formalize scenarios in a hierarchical task model to design an adaptive E-learning system.

Now, we need to describe scenarios in detail. In other words, the co-design process has to go to the next loop of our swirl model. A particular scenario was done according to the proposed transposition - the more complex one. The next issues are: i) to make all scenarios according to this transposition with more details; ii) to carry out experiments to get adaptation criteria from these scenarios; iii) to define the corresponding generic scenario and its adaptation policies; iv) to design a hierarchical task model able to deal with these adaptation policies and thus to implement a first version of the e-learning system; v) to design the different ontologies. A first version of the domain ontology has been done; vi) to establish the real benefits and the limits of the Chevallard theory and also to investigate and use the other theories.

\section{References}

1. Tchounikine, P., Pour une ingénierie des Environnements Informatiques pour l'Apprentissage Humain. Revue I3, 2002. 2(1): p. 59-95.

2. Duursma, C. and O. Olsson, Task Model definition and Task Analysis. 1993, Vrije University.

3. Willamowski, J., Modélisation de tâches pour la résolution de problèmes en coopération systèmeutilisateur. 1992, Université Joseph Fourier: Grenoble.

4. Wielinga, B., et al. The KADS Knowledge Modelling Approach. in Proceedings of the 2nd Japanese Knowledge Acquisition for Knowledge-Based Systems Workshop. 1992. Hatoyama, Saitama, Japan: Hitachi, Advanced Research Laboratory.

5. Trichet, F., DSTM: un environnement de modélisation et d'opérationalisation de la démarche de résolution de problèmes d'un Système à Base de Connaissances. 1998, Université de Nantes: Nantes.

6. Akrich, M., M. Callon, and B. Latour, A quoi tient le succès des innovations. Annales des Mines, 1998: p. 417.

7. Engeström, Y. and M. Cole, A cultural-historical approach to distributed cognition, in Distributed cognition. Psychological and educational considerations, G. Salomon, Editor. 1993, Cambridge University Press. p. 1-46.

8. Brousseau, G., Théorie des situations didactiques. 1998, Grenoble: La Pensée Sauvage.

9. Chevallard, Y., Concepts fondamentaux de la didactique : perspectives apportées par une approche anthropologique. La Pensée sauvage, Recherches en didactique des mathématiques, Grenoble, 1992. 12(1): p. 77-111.

10. Chevallard, Y., L'analyse des pratiques enseignantes en théorie anthropologique du didactique. La Pensée sauvage, Recherches en didactique des mathématiques, Grenoble, 1999. 19(2): p. 221-226.

11. Wenger, E., Communities of Practice - Learning, Meaning and Identity. Learning in Doing: Social, Cognitive and Computational Perspectives. 1998, Cambridge: Cambridge University Press.

12. Perrennoud, P., La transposition didactique à partir de pratiques : des savoirs aux compétences. Revue des sciences de l'éducation, Montréal, 1998. XXIV(3): p. 487-514.

13. Garlatti, S. and S. Iksal, A Flexible Composition Engine for Adaptive Web Sites, in Adaptive Hypermedia and Adaptive Web-Based Systems, AH 2004, P.D. Bra and W. Nejdl, Editors. 2004, Springer Verlag. p. 115-125.

14. Iksal, S. and S. garlatti. Adaptive Web Information Systems: Architecture and Methodlogy for Reusing Content. in AH 2004 workshops, EAW'04: Engineering the Adaptive Web. 2004. Eindhoven: Technishe Universiteit Eindhoven. 
15. Garlatti, S., S. Iksal, and P. Tanguy, SCARCE: an Adptive Hypermedia Environment Based on Virtual Documents and Semantic Web, in Adaptable and Adaptive Hypermedia Systems, S.Y. Chen and G.D.

Magoulas., Editors. 2004, Idea Group Inc. p. 206-224. 